\title{
Angiogenic Properties of Natural Rubber Latex Biomembranes and The Serum Fraction of Hevea brasiliensis
}

\author{
Mariselma Ferreira* \\ Departamento de Física e Matemática FFCLRP-USP and \\ Centro de Ciências Naturais e Humanas CCNH-UFABC \\ Ricardo José Mendonça and Joaquim Coutinho-Netto \\ Departamento de Bioquímica FMRP-USP \\ Marcelo Mulato \\ Departamento de Física e Matemática FFCLRP-USP
}

(Received on 5 May, 2009)

\begin{abstract}
The angiogenic properties of natural rubber were evaluated in this work. We have used the chick chorioallantoic membrane assay (CAM) as a model to investigate the influence of the heating on biological activity in rubber membranes and in non rubber fraction as well. Results showed that natural rubber membranes can induce vascularization. It was observed that angiogenesis activity was maximum when membranes were heated in temperatures between $65^{\circ} \mathrm{C}$ and $85^{\circ} \mathrm{C}$, considering a range from $55^{\circ} \mathrm{C}$ to $105^{\circ} \mathrm{C}$. The same behavior was observed for non rubber fraction and it indicates that this serum fraction may be responsible for angiogenesis. When infrared spectroscopy was performed in the cast films of non rubber fraction samples, as a function of heating, no structural changes was observed. The results obtained shown that natural rubber latex films produced by casting induce the vessel growth in the CAM and it can be considered as a potential biomaterial.
\end{abstract}

Keywords: Biomatherials; Hevea brasiliensis; Natural Latex; Rubber; Angiogenesis

\section{Introduction}

Angiogenesis is fundamental for living organisms in processes such as organ growth, reproduction and wound repair. It is characterized by in situ formation of blood vessels, thus permitting proliferation, migration, regulation and differentiation of vascular cells. When well regulated, angiogenesis occurs for a given period of time until the physiological aim is achieved. On the other hand, angiogenesis is also involved in the development of diseases, including tumors and arthritis. The mechanism of angiogenesis regulation is still a matter of debate. Some angiogenic molecules, referred to as Growth Factors, are known to trigger proliferation of endothelial cells [1,2], while the so-called antiangiogenic factors inhibit cell propagation [3]. Though some of these molecules have been identified and investigated for more than two decades [1], many questions remain as how they activate and regulate the normal and abnormal angiogenesis [4]. Folkman and collaborators [1] classified 8 angiogenic polypeptides according to their biological activity, which included the polypeptides FGF (fibroblast growth factor) and VEGF (vascular endothelial growth factor). The first occurs in two forms, the acid and basic fibroblast growth factor (aFGF and bFGF respectively), being mitogenic for various cell types. VEGF is specific for vascular endothelial cells and increases the vascular permeability $[5,6]$.

Angiogenesis has also been an important topic in cancer research, wound healing and tissue engineering [7-13]. Materials have been developed in tissue engineering, which incorporate angiogenic molecules in the matrix (therapeutic angiogenesis). These bioactive materials are generally devel-

*Electronic address: mariselma.ferreira@ufabc.edu.br oped as coatings to enhance cell proliferation or as curatives to promote wound healing $[10,11]$, by inducing localized growth of blood vessels in the tissue. Biopolymeric delivery matrices for angiogenic growth factors may be obtained from natural and synthetic polymers and macromolecules such as polysaccharides (chitosan, hyaluronan, agarose) [7]. The matrices are required to be immunogenic and must have no inflammation reactions with the body environment. In addition, the immobilized growth factors must remain functional during material fabrication and after its implantation [7]. In their review paper, Zisch and coworkers emphasized as a key feature for the matrices the controlled release of the growth factor, because unregulated diffusion may induce formation of dense, unstable vessels [7]. A methodology to improve cell seeding and growth was based on the immobilization of the polysaccharide heparin and bFGF in a collagen matrix [12], with heparin binding to FGFs and improving their immobilization and prolonged release. In fact, heparin-like molecules help maintaining the biological activity of growth factors [14]. Heparin was also used with aFGF immobilized in layer-by-layer (LbL) films, which included cell culture tests to verify bioactivity of the films [15].

The studies mentioned above all shared the goal of changing an inert surface (made of synthetic or natural polymer) into a bioactive material to promote in situ angiogenesis and enhance cell proliferation.

The technological importance of natural rubber is well known, but in medicine this material has been restricted to use in condoms and surgical gloves. In 1963, Sharp and coworkers obtained relatively poor results with introduction of a rubber latex tube into the abdominal aorta of a dog [16]. While the rubber latex was found to possess many properties of an ideal vascular substitute, such as elasticity, it displayed a poor support for neointima formation. In later works, deficiencies in neointimal development could be corrected by addition of an electrically conductive layer to the 
rubber $[17,18]$. More recently, natural rubber has been reported as potential biomaterial [19-22], and a material based on natural latex showed induction of wound healing in the esophageal wall of dogs, attributed to a marked increase in vascularization (angiogenesis) [20]. A similar material was used to treat leg ulcers with clear signs of granulation accompanied by reduction in the patient's pain [19]. The latter work was the first to demonstrate the potential of natural rubber latex for tissue regeneration, and has generated a commercial curative [23] already approved by ANVISA, the Brazilian government authority responsible for regulating health devices. As it has been suggested [19] that NR latex may contain vascular growth factors that act on human tissue, it can enhance local vascularization and induce angiogenesis.

\section{Natural rubber (Hevea brasiliensis)}

Natural rubber (NR) latex extracted from the Hevea brasiliensis is a polydisperse system containing 30-45\% weight of rubber molecules (cis-polyisoprene), 4-5\% weight of non-rubber constituents such as protein, lipids, carbohydrates and sugar and $50 \%$ of water [24, 25]], Figure 1 . The latex composition depends on the season of the year for the extraction and age of the tree [26].

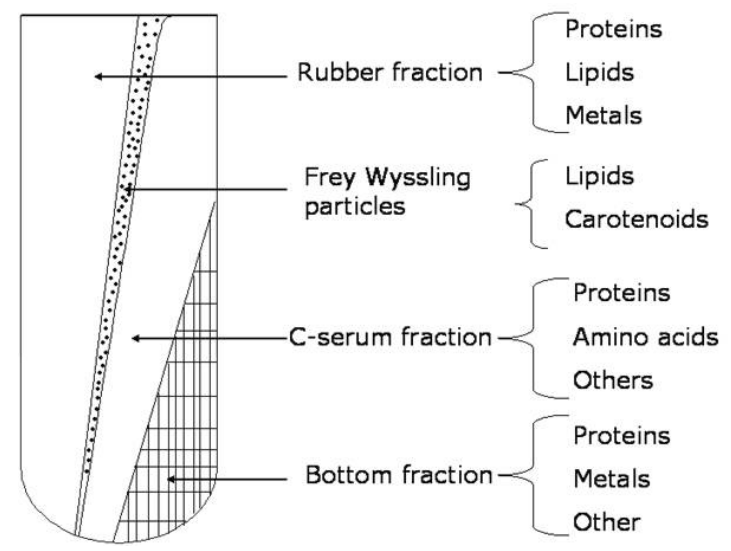

FIG. 1: Fractions of natural rubber latex after centrifugation [19]

Natural rubber is a naturally occurring form of cis isoprene, Figure 2, and exhibits elastomeric behavior upon intermolecular crosslinking (i.e. vulcanization). The rubber particles are surrounded by protein anions and are effectively negatively charged. When exposed to air, latex coagulation occurs as proteins are decomposed rapidly by bacteria and enzymes, while crosslinking within the rubber particles leads to degradation of the rubber chains. Natural rubber is an important raw material for a large range of industrial applications such as tires, automobile, shoes and aircrafts. As the living cytoplasm of laticeferous cells, Hevea brasiliensis latex is a rich blend of organic substances that include many different proteins comprising about $1 \%$ to $1.5 \%$ of this latex system. The bulk of these proteins is removed when the latex is processed into its products, remaining only a small fraction in the product denominated residual extractable proteins (EPs). Yip et al. showed that high EP levels are associated with positive skin prick test responses [27,28]. EP level lower than $400 \mu \mathrm{g} / \mathrm{g}$ of glove tested in individuals with latex allergy showed that $60 \%$ did not have a positive response, and in levels of about $100 \mathrm{~g} / \mathrm{g}$ and less, the percentage of non responders reached about $100 \%$. A few of these proteins are recognized allergens by the International Union of Immunological Societies (IUIS). Allergic reactions to rubber products, made from both natural and a wide variety of synthetic rubbers, have been known for many years, but the vast majority of these reactions (usually known as Type IV allergies) can be traced to the residues from accelerators and other compounding ingredients. Natural rubber latex products had been marketed on a relatively large scale for the last fifty years without any serious suspicion of health risk to the users. Examples of products include baby bottle teats, elastic thread, gloves, condoms, foam rubber mattresses, pillows and adhesives.

A systematic study of the angiogenic NR is lacking, however, and this is the topic addressed in the present paper. We use the chick chorioallantoic membrane assay as a model and investigate the influence from membrane fabrication parameters (heating) on the biological activity. Furthermore, we separated the serum from the rubber fraction and studied the effects from heating in the angiogenic activity of nonrubber components as well.

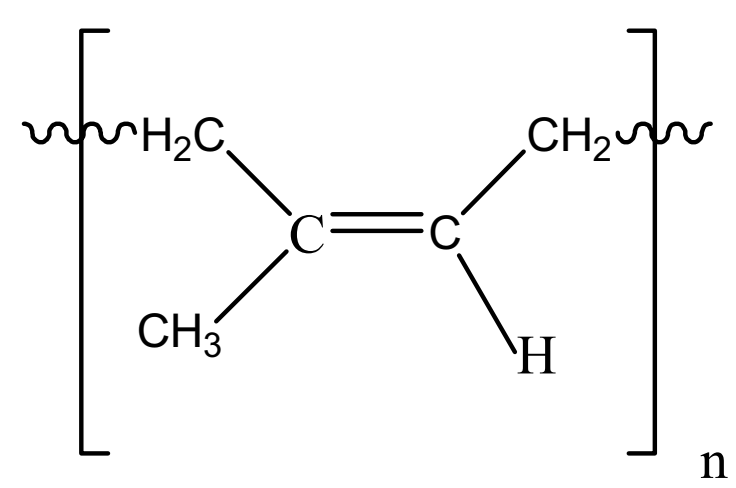

FIG. 2: Cis polyisoprene monomer

\section{Materials and Methods}

\section{Sample Preparation}

Freshly tapped natural rubber latex was extracted from RRIM-600 clone of Hevea brasiliensis and stabilized with ammonia to avoid coagulation. To study the influence from temperature in the angiogenic activity, approximately $2.5 \mathrm{~mL}$ of latex was deposited in a Petri dish and dried during 2.5 hours in an oven with controlled temperature. The samples were prepared varying the drying temperature ranging from $45^{\circ} \mathrm{C}$ to $105^{\circ} \mathrm{C}$. The film was detached from the Petri dish and sterilized with ethylene oxide at the Clinical Hospital of the Faculty of Medicine of Ribeiro Preto-SP. Prior to the experiments in vivo, the membranes were cut in pieces of approximately $0.5 \mathrm{~cm}$ with a sterilized knife. The experimental tests were performed using the choriolantoic membrane 
assay during 15 months, totalizing 15 experiments. For each experiment we investigated 4 samples in six distinct temperatures $\left(45^{\circ} \mathrm{C}, 55^{\circ} \mathrm{C}, 65^{\circ} \mathrm{C}, 75^{\circ} \mathrm{C}, 85^{\circ} \mathrm{C}, 95^{\circ} \mathrm{C}\right)$. Considering this range of data, we used the Excel software for determine the Average and Standard Deviation of the data, which were showed in the figures 4 and 6 .

We also investigated the angiogenic response of the nonrubber constituents of natural rubber, ie. the serum fraction in the absence of rubber particles. The latex stabilized with ammonium was submitted to a coagulation process by addition of acetic acid $(2.0 \% \mathrm{v} / \mathrm{v})$. The coagulation takes place when $\mathrm{pH}$ falls below 5.0, and the latex is separated into two parts: the rubber fraction and the serum fraction (nonrubber constituents). The serum fraction was purified in a column of DEAE-cellulose $(5 \times 40 \mathrm{~cm})$ eluted with stepwise gradient of $\mathrm{NH}_{4} \mathrm{HCO}_{3} / \mathrm{NaCl}$. From this purification, three fractions were obtained by exclusion based on the charge affinity with the DEAE column. Each fraction was dialyzed and lyophilized.

The first fraction (FrHB1) eluted from the separation column had the most evident angiogenic effects in the CAM assays [29]. Therefore, we submitted this most active fraction (FrHB1) to the thermal treatment and evaluated the angiogenic response. The lyophilized (FrHB1) fraction was weighted and dissolved in distilled water $(2.5 \mathrm{mg} / \mathrm{mL})$. Then, a $3 \mu L$ droplet of this solution was pipetted on the filter disc papers $(0.5 \mathrm{~cm}$ diameter $)$. These discs were left to dry at room temperature and after been dried the testing samples were heated in an oven in temperatures ranging from 45$105^{\circ} \mathrm{C}$ to simulate the thermal treatment performed with the NR membranes. After the heating process, the sample containing serum fraction was placed on chorioallantoic membrane for evaluation of the angiogenic activity.

\section{Chorioalantoic membrane assay}

The chick embryo choriolantoic membrane (CAM) was first described by embryologists, being the most widely used system for studying angiogenesis [30]. Fertilized eggs were purchased from Pena Branca Company (São Carlos, SP) and placed in an incubator at $38{ }^{\circ} \mathrm{C}$ with $65-70 \%$ relative humidity. The incubator (Brasmatic Ind. Com. LTDA, So Paulo, Brazil) was equipped with a temperature controlling system. On the fifth day of incubation the eggs were cleansed with $70 \%$ ethanol and opened using a circular drill (Dremel Multipro, Breda, USA). The cap was removed and the shell membranes were moisturized with a sterilized saline solution to help the complete detachment of the shell from the CAM. Eggs were then incubated again and at the thirteenth day of incubation the test samples were applied on the CAM. At day 17 (of incubation), the embryos were sacrificed by addition of formaldehyde $10 \%$. Digital images of the CAM were captured using an optical microscope with a $C C D$ video camera (Sony Model DXC-107A). Image data were captured and analyzed with commercial software (PixelViewStation v5.19TV). The amount of vessels was quantified using other commercial software (ImageJ1, 32J, NH, USA) commonly used for quantifying pixels in digitalized images. The results presented in Figures 4 and 6 (circles) show an aver- age of amount of vessels obtained for data acquired in fifteen months. All the experimental manipulations were done with sterile instruments (glassware and tweezers), but we did not manipulate the opened eggs in a tissue-culture hood.

\section{FTIR}

The FTIR measurements were carried out with a Nicolet equipment in the cast films fabricated by dropping $20 \mathrm{~L}$ of a $2.5 \mathrm{mg} / \mathrm{mL}$ serum fraction solution onto gold substrates. The substrates were heated to temperatures between $45^{\circ}$ and $105^{\circ} \mathrm{C}$. The solution was prepared using Milli-Q water.

\section{Results and Discussion}

The effects from thermal treatment on the angiogenic activity of natural rubber are illustrated in Figures 3.a)-f), which show the membranes placed in the CAM for heating temperatures ranging from 55-105 $\circ \mathrm{C}$. A qualitative examination of the CAM images shows no change in the vessels density for temperatures between $55^{\circ}$ and $65^{\circ} \mathrm{C}$. In contrast, for temperatures between $75 \circ$ and $85^{\circ} \mathrm{C}$, a red region marked by an arrow appears in Figures 3 e)-g), which is indicative of rubber angiogenesis. The difference is clear upon comparing Figures $3 \mathrm{~d}$ and $3 \mathrm{e}$ with the control membranes. For membranes heated from $95^{\circ}-105^{\circ} \mathrm{C}$ no changes in the vessel density could be observed in the CAM companying with the control membranes.

The angiogenic activity may be evaluated quantitatively by counting the number of vessels in the graph of Figure 4. The amount of vessels presented shows an average of the fifteen experiments performed for each temperature. The error bars on Figure 4 show the standard deviation (SD) of data. In spite of the dispersion in the data points (to be discussed below), the activity for the thermally-treated NR membranes in Figure 3 is always higher than the control sample made with synthetic material (black dashed line). An optimized temperature for treating the membranes is between $65 \circ \mathrm{C}$ and $85^{\circ} \mathrm{C}$, where angiogenesis activity was maximum.

The large dispersion in the data (i.e. large error bars) may have several sources. First, NR does possess different properties depending on the period of collection (seasonal variation) and storage time [24,26,31]. Indeed, an inspection of our results points to differences in the activity for membranes stored for different periods of time. This may be due to the poor stability of non-rubber constituents of NR, especially in the presence of ammonium [31]. Most affected are the lipids, which are major components surrounding the rubber particles in the latex. The latex used here was collected in three different seasons over 15 months of studies. Though we took precautions in keeping the samples in a refrigerator and with ammonium to minimize errors, variations could still exist. In addition, non-homogeneity in the membranes was observed even for samples prepared with the same latex, in the same day.

Since NR comprises a rubber fraction and non-rubber constituents, we have extracted the non-rubber fraction to investigate its angiogenic activity. The results are shown in 


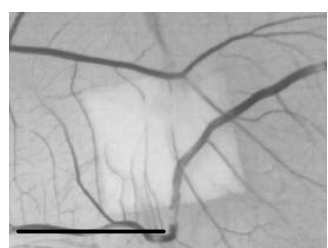

Fig. 3. a)

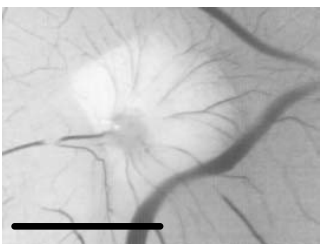

Fig.3.b)

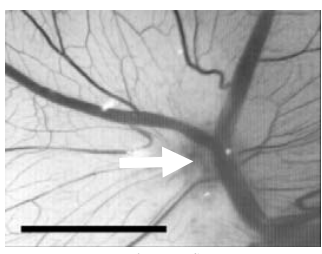

Fig.3.d)

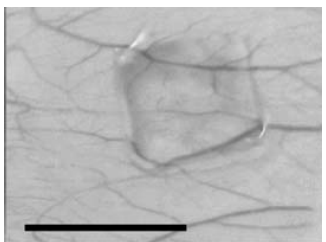

Fig.3.f)

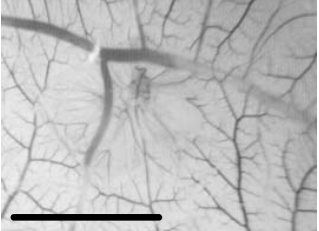

Fig.3.c)

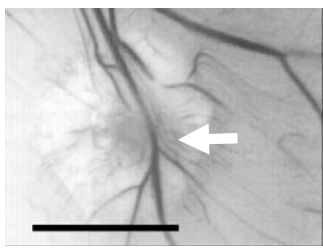

Fig. 3. e)

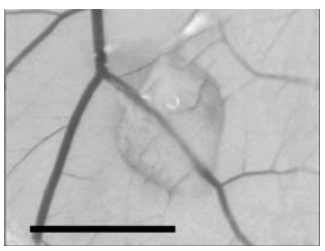

Fig.3.g)

FIG. 3: Vascular networking formation induced by the rubber membranes placed on the top of the chicken chorioallontoic membrane for different temperatures. a) Control (synthetic isoprene); b) 55 ${ }^{o} \mathrm{C}$; c) $65^{\circ} \mathrm{C}$; d) $75^{\circ} \mathrm{C}$; e) $85^{\circ} \mathrm{C}$; f) $95^{\circ} \mathrm{C}$; g) $105^{\circ} \mathrm{C}$

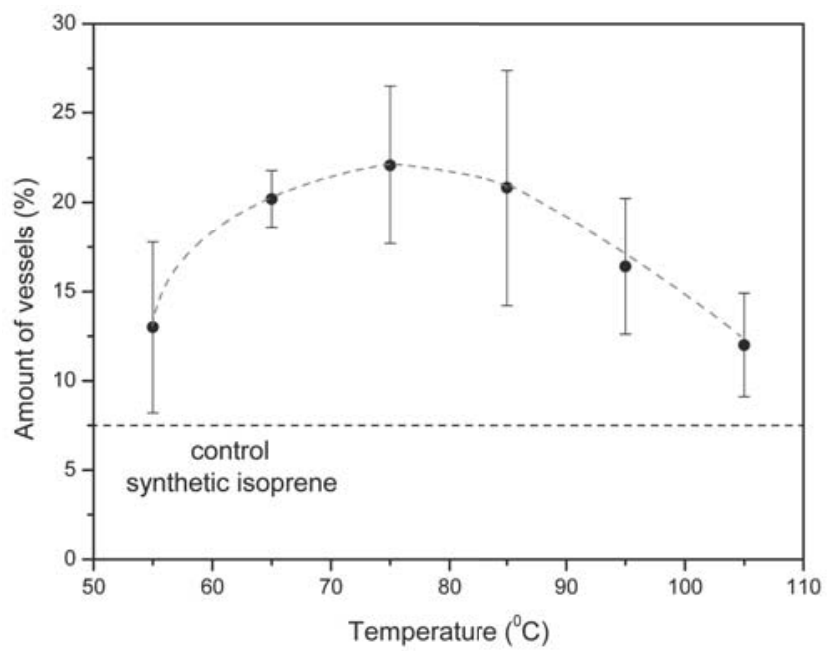

FIG. 4: Percentage of vessels as a function of membrane heating ( $\mathrm{N}$ ranging from 10-15). The red dashed line has been drawn just to guide the eye. Errors bars show standard deviation (SD).

Figures 5 a)-g), where a circle was added to the image of Figure 5a for the control experiment to mark where there is no modification in the number of vessels. A visual inspection points to stronger angiogenic activity for samples treated from $65-85^{\circ} \mathrm{C}$, as indicated by the arrows.

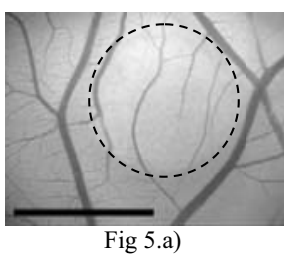

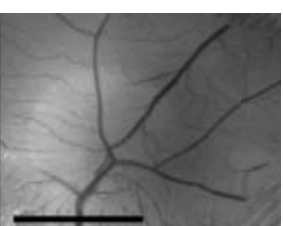

Fig.5.b)
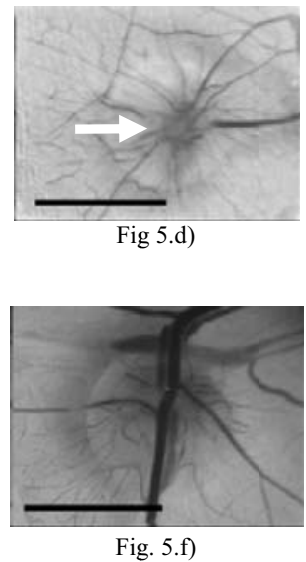

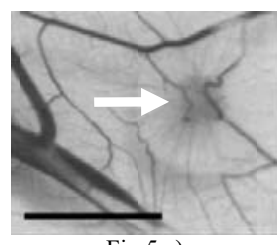

Fig.5.c)

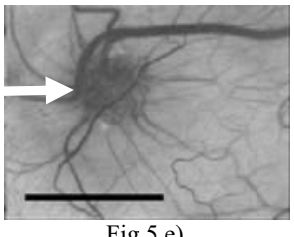

Fig.5.e)

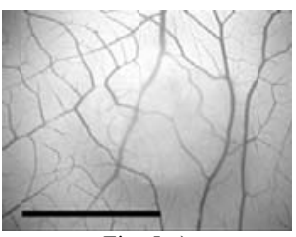

Fig. 5.g)
FIG. 5: Vascular networking formation induced by non-rubber serum fraction placed on the top of the chicken chorioallontoic membrane. a) Control (distilled water); b) $55^{\circ} \mathrm{C}$; c) $65^{\circ} \mathrm{C}$; d) 75 ${ }^{o} \mathrm{C}$, e) $85^{\circ} \mathrm{C}$. f) $95^{\circ} \mathrm{C}$; g) $105^{\circ} \mathrm{C}$.

The results of Figure 5 can be quantified, as depicted in Figure 6, which again shows enhanced angiogenic activity for almost all membranes, in comparison with the synthetic substrate. Analogously to the results for the NR membranes (Figure 4), angiogenic activity is maximum for thermal treatments in the region of $70-85^{\circ} \mathrm{C}$. The dispersion in the data, however, is now significantly less than for NR, what was expected as the serum material is more homogeneous than the NR membranes.. Considering that the temperature range was essentially the same for NR and serum membranes, results indicate that the non-rubber serum fraction may be responsible for angiogenesis. The trangles represent an average for data acquired in temperature points of $70^{\circ} \mathrm{C}$ and $80^{\circ} \mathrm{C}$ not evaluated for NR membranes (Figure 4).

Cast films from the serum fraction were analyzed with FTIR spectroscopy, and the results are shown in Figure 7 for samples treated at various temperatures. The features in the spectra are probably associated with the secondary struc- 


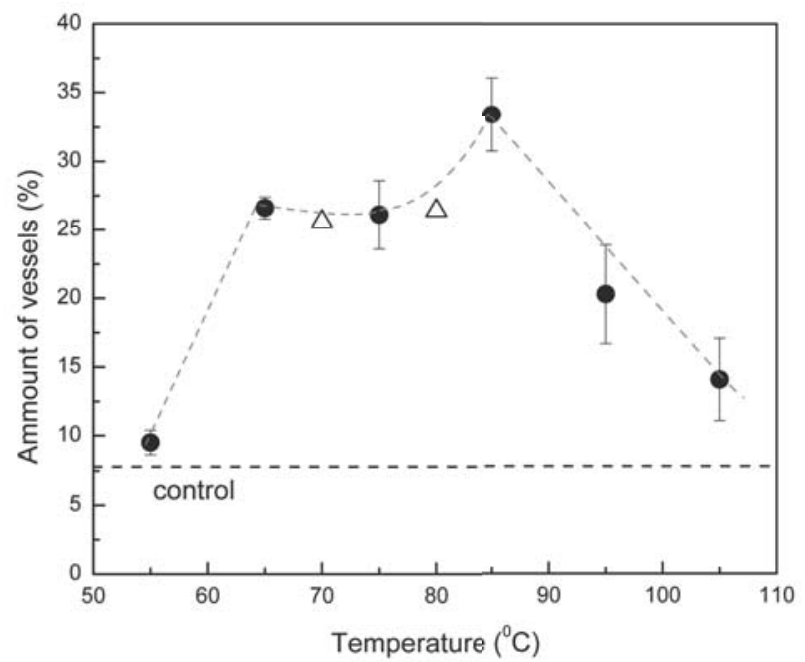

FIG. 6: Percentage of vessels vs. temperature for thermal treatment of films made with NR serum (N ranging from 5-10). The triangles represent an average for data acquired in temperature points of 70 ${ }^{\circ} \mathrm{C}$ and $80{ }^{\circ} \mathrm{C}$. The red dashed line is just to guide the eye. Errors bars show standard deviation (SD).

ture of proteins, as identified by the amide bands (amide I $1620-1700 \mathrm{~cm}-1$ ) and amide II - 1520-1580 cm-1) [32,33]. This region is represented between dashed lines in Figure 7. Because the samples investigated here comprise a mixture of non-rubber materials, and not isolated proteins, we cannot identify which type of secondary structure is being affected by the temperature in the thermal treatment. Nevertheless, one infers from Figure 7 that the conformation of the NR serum fraction does vary with the temperature.

\section{Conclusions}

The present study has shown a systematic evaluation of the natural rubber angiogenic properties using the CAM method. The results obtained shown that the natural rubber latex films produced by casting induces the vessel growth in the CAM and it can be considered as a potential biomaterial. The angiogenic evaluation according to the heat treatment of the NR latex film revealed that the angiogenic behavior remains active and increase in temperatures ranging from $65-85^{\circ} \mathrm{C}$. It is particularly interesting, since the NR films are prepared by heating the latex system. The results showed here may suggest a maximum temperature $\left(85^{\circ} \mathrm{C}\right)$ to be used for this procedure.

The second important effect achieved in this study was the demonstration that the bioactive fraction of the NR latex is the non-rubber constituents of the latex systems and the polyisoprene chains are not the main responsible for these mate- rial activity. Here we proposed an easy method to isolate the angiogenic fraction from NR latex. The curve for the percentage of vessels as a function of heating for NR film and NR serum was very similar and it suggests that the active fraction extracted from the rubber could be study to be incorporated in other systems such as thin polymer films.

The FTIR experiments suggested changes in the sec-

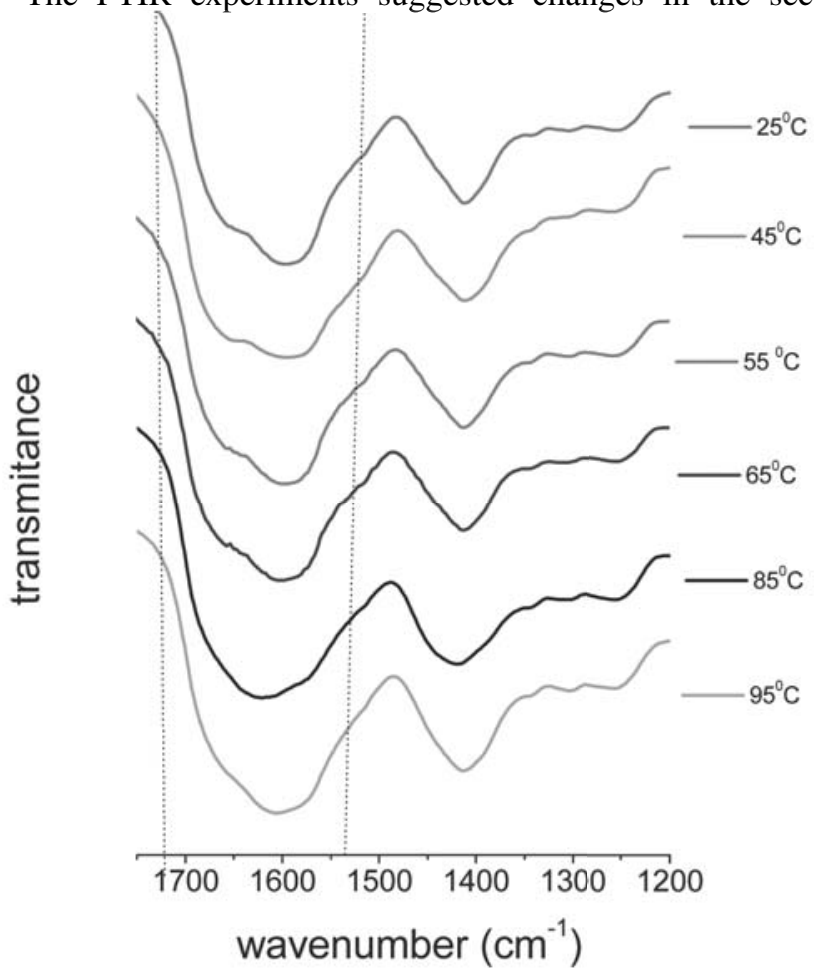

FIG. 7: FTIR spectra of the NR serum fraction for different temperatures of heating.

ondary structure of the NR serum fraction as a function of heating. However, the fact we did not have a completely purified angiogenic fraction turned difficulty the evaluation of the structural changes as a function of heating. One of the suppositions is that the variation in the secondary structure can exhibit the angiogenic part of the NR bioactive protein and increase the potential behavior of the material.

\section{Acknowledgement}

FAPESP (03/02516-2); CNPq (420198/2005-9) and (478452/2004-7); Prof. Osvaldo Novais de Oliveira Jr. Polymer Group of IFSC-USP; Prof. Carlos F. de O Graeff; and Prof. Marcos Bernardes, for the latex sample donation.
[1] Folkman J, Shing Y. Angiogenesis. The Journal of biological chemistry. 1992 Jun 5;267(16):10931-4.

[2] Wilting J, Brand-Saberi B, Kurz H, Christ B. Development of the embryonic vascular system. Cellular \& molecular biology research. 1995;41(4):219-32.

[3] Folkman J. Endogenous angiogenesis inhibitors. Apmis. 2004 Jul-Aug;112(7-8):496-507.

[4] Ferrara N. Role of vascular endothelial growth factor in 
the regulation of angiogenesis. Kidney international. 1999 Sep;56(3):794-814.

[5] Ferrara N, Gerber HP, LeCouter J. The biology of VEGF and its receptors. Nature medicine. 2003 Jun;9(6):669-76.

[6] Helmlinger G, Endo M, Ferrara N, Hlatky L, Jain RK. Formation of endothelial cell networks. Nature. 2000 May 11;405(6783):139-41.

[7] Zisch AH, Lutolf MP, Hubbell JA. Biopolymeric delivery matrices for angiogenic growth factors. Cardiovasc Pathol. 2003 Nov-Dec;12(6):295-310.

[8] Folkman J. Angiogenesis and apoptosis. Seminars in cancer biology. 2003 Apr;13(2):159-67.

[9] Gupta MK, Qin RY. Mechanism and its regulation of tumor-induced angiogenesis. World J Gastroenterol. 2003 Jun;9(6):1144-55

[10] Schultz GS, Sibbald RG, Falanga V, Ayello EA, Dowsett C, Harding K, et al. Wound bed preparation: a systematic approach to wound management. Wound Repair Regen. 2003 Mar;11 Suppl 1:S1-28.

[11] Shen JT, Falanga V. Innovative therapies in wound healing. Journal of cutaneous medicine and surgery. 2003 MayJun; 7(3):217-24.

[12] Wissink MJ, Beernink R, Poot AA, Engbers GH, Beugeling T, van Aken WG, et al. Improved endothelialization of vascular grafts by local release of growth factor from heparinized collagen matrices. J Control Release. 2000 Feb 14;64(1-3):10314.[13]

[13] Folkman J, Kalluri R. Cancer without disease. Nature. 2004 Feb 26;427(6977):787.

[14] Prestrelski SJ, Fox GM, Arakawa T. Binding of heparin to basic fibroblast growth factor induces a conformational change. Archives of biochemistry and biophysics. 1992 Mar;293(2):314-9.

[15] Mao Z, Ma L, Zhou J, Gao C, Shen J. Bioactive thin film of acidic fibroblast growth factor fabricated by layer-by-layer assembly. Bioconjugate chemistry. 2005 Sep-Oct;16(5):131622.

[16] Sharp WV, Falor WH. Rubber latex tubing as a vascular prosthesis. American journal of surgery. 1963 Jun;105:802-11.

[17] Sharp WV. Vascular prostheses. Transactions - American Society for Artificial Internal Organs. 1964;10:223-6.

[18] Sharp WV, Gardner DL, Andresen GJ. Adaptation of Elastic Materials for Small Vessel Replacement. Transactions - American Society for Artificial Internal Organs. 1965;11:336-40.

[19] Frade MA, Valverde RV, de Assis RV, Coutinho-Netto J, Foss NT. Chronic phlebopathic cutaneous ulcer: a therapeutic proposal. International journal of dermatology. 2001 Mar;40(3):238-40.

[20] Mrué F. Neoformação tecidual induzida por biomembrana de látex natural com poli-lisina. Aplicabilidade na neoformação esofágica e da parede abdominal. Estudo experimantal em cães. Ribeirão Preto: Faculdade de Medicina de Ribeirão Preto - USP; 2000.

[21] Neves Junior WP, Ferreira M, Alves MCO, Graeff CFO, Mulato M, Coutinho-Netto J, et al. Influence of fabrication process on the final properties of Natural-Rubber Latex tudes for vascular prothesis. Brazilian Journal of Physics. 2006;36(2B):586-91.

[22] Neves Junior WP, Graeff CFO, Ferreira M, Mulato M, Bernardes M, Coutinho-Netto J. Influence of the fabrication process on the final properties of vascular prothesis made of natural rubber latex. Journal of Applied Polymer Science. 2006;100:702-7.

[23] Mrué F, da Silva Zborowski AC, inventors; Biomembrane suitable for use in substituition, reconstruction of angiogenesis, neoformation or regeneration of human or animal organs or tissues. European Union. 2006.

[24] Grave H-H, Bayer AG, Leverkusen AG. Ullmanns Encyclopedia of Industrial Chemistry 1993:221-35.

[25] Hasma H. Journal of Natural Rubber Research. 1993;12:2132.

[26] Ferreira M, Moreno RMB, Goncalves PS, Mattoso LHC. Evaluation of natural rubber from clones of Hevea brasiliensis. Rubber Chemistry and Technology. 2002 Mar-Apr;75(1):1717.

[27] Yip E, Sussman G. Allergenicity of latex gloves with reference to latex protein sensitive individuals in a canadian population. Journal of Natural Rubber Research. 2000;3(3):129-41.

[28] Yip E, Turjanmaa K, Ng KP, Mok KL. Residual estractable proteins and allergenicity of natural rubber products. Journal of Natural Rubber Research. 1994;9:79-86.

[29] Mendonça RJ. Caracterizaç ao biolgica de uma fração angiogênica do látex natural da seringueira Hevea brasiliensis. Ribeiro Preto: USP; 2004.

[30] Auerbach R, Kubai L, Knighton D, Folkman J. A simple procedure for the long-term cultivation of chicken embryos. Developmental biology. 1974 Dec;41(2):391-4.

[31] Hasma H. Lipids associated with rubber particles and their possible role in mechanical stability of latex concentrates. Journal of Natural Rubber Research. 1991;6(2):105-14.

[32] Havel HA, Chao RS, Haskell RJ, Thamann TJ. Investigations of Protein-Structure with Optical Spectroscopy Bovine Growth-Hormone. Analytical chemistry. 1989 Apr $1 ; 61(7): 642-50$.

[33] Wittemann A, Ballauff M. Secondary structure analysis of proteins embedded in spherical polyelectrolyte brushes by FT-IR spectroscopy. Analytical chemistry. 2004 May 15;76(10):2813-9. 